\title{
Supervisi Klinis oleh Kepala Sekolah guna Meningkatkan Kompetensi Guru dalam Mengelola Administrasi Kelas di SD Negeri 42 Ampenan
}

\author{
Tri Wahyuni \\ SD Negeri 42 Ampenan, Kota Mataram - Provinsi NTB \\ Corresponding Author. Email: triwahyuni@gmail.com
}

\begin{abstract}
This study aims to improve the ability of teachers to organize their Article History classes, improve teacher professionalism in carrying out their main tasks and Received: 11-02-2021 functions as teaching staff, increase teacher insight and knowledge about teacher Revised: 13-03-2021 competencies and improve the quality of teachers in managing classroom Published: 04-04-2021 administration through clinical supervision. This research method uses school action research. The subjects in this study were 13 teachers of SD Negeri 42 Ampenan. Data collection techniques using observation, interviews, and documentation. The data analysis technique used in this research was qualitative Key Words: and quantitative descriptive analysis. The results of this study indicate that the Clinical Supervision, ability of teachers to manage classroom administration can be improved by Teacher Competence, providing clinical supervision.

Mengelola Administrasi.
\end{abstract}

\begin{abstract}
Abstrak: Penelitian ini bertujuan untuk meningkatkan kemampuan guru dalam Sejarah Artikel mengatur kelasnya, meningkatkan profesionalisme guru dalam melaksanakan Diterima: 11-02-2021 tugas pokok dan fungsinya sebagai tenaga pengajar, menambah wawasan dan Direvisi: 13-03-2021 pengetahuan guru tentang kompetensi guru serta meningkatkan mutu guru dalam Diterbitkan: 04-04-2021 mengelola administrasi kelas melalui supervisi klinis. Metode penelitian ini menggunakan penelitian tindakan sekolah. Subjek dalam penelitian ini adalah guru SD Negeri 42 Ampenan yang berjumlah 13 guru. Teknik pengumpulan datanya menggunakan observasi, wawancara, dan dokumentasi. Teknik analisis Kata Kunci: data penelitian ini menggunakan analisis deskriptif kualitatif dan kuantitatif. Hasil Supervisi Klinis, penelitian ini menunjukkan bahwa kemampuan guru dalam mengelola administrasi Kompetensi Guru, kelas dapat meningkat dengan diadakannya supervisi klinis.

Mengelola Administrasi.
\end{abstract}

How to Cite: Wahyuni, T. (2021). Supervisi Klinis oleh Kepala Sekolah guna Meningkatkan Kompetensi Guru dalam Mengelola Administrasi Kelas di SD Negeri 42 Ampenan. Jurnal Paedagogy, 8(2). doi:https://doi.org/10.33394/jp.v8i2.3561

https://doi.org/10.33394/jp.v8i2.3561

This is an open-access article under the CC-BY-SA License.

\section{Pendahuluan}

Pendidikan Nasional bertujuan untuk berkembangnya potensi peserta didik agar menjadi manusia yang beriman dan bertaqwa kepada Tuhan Yang Maha Esa, beraklaq mulia sehat, berilmu, cakap, kreatif, mandiri, dan menjadi warga negara demokratis serta bertanggung jawab (UU No. 20 Tahun 2003, dalam Depdiknas 2007). Sehubungan dengan keluarnya UU No. 20 Tahun 2003 Tentang sistem Pendidikan Nasional Kemudian disusul Peraturan pemerintah No. 19 Tahun 2005 Tentang Standar Nasional Pendidikan (SNP) khususnya pasal 57, supervisi manajerial dan akademik dilakukan secara teratur dan berkesinambungan oleh Kepala Sekolah dan Kepala Satuan Pendidikan. Berdasarkan ketentuan tersebut di atas, sangat penting untuk mengetahui daya serap seorang guru dalam mengelola administrasi kelas.

Administrasi kelas adalah segala usaha yang diarahkan untuk mewujudkan suasana belajar mengajar yang efektif dan menyenangkan serta dapat memotivasi siswa untuk belajar dengan baik sesuai dengan kemampuan. Atau dapat dikatakan bahwa manajemen kelas merupakan usaha sadar untuk mengatur kegiatan proses belajar mengajar secara sistematis. 
Usaha sadar itu mengarah pada pengaturan ruang belajar, mewujudkan situasi/kondisi proses belajar, mengajar dan pengaturan waktu sehingga pembelajaran berjalan dengan baik dan tujuan kurikuler dapat tercapai (Dirjen PUOD \& Dikdasmen, 1996). Administrasi kelas sebagai cermin dalam pendidikan atau proses belajar mengajar. Oleh karena itu, guru harus di supervisi manejerial dalam pengelolaan administrasi kelas.

Agar proses pendidikan dapat berjalan efektif dan efisien, guru dituntut memiliki kompetensi yang memadai, baik dari segi jenis maupun isinya (Kadri, 2016; Kamaludin, 2016; Purnamaraya, 2019). Di dalam PP RI No. 19 tahun 2005 tentang SNP pada apasal 28 ayat 3 disebutkan ada 4 dimensi kompetensi guru, yaitu: kompetensi pedagogik, kompetensi kepribadian, kompetensi sosial dan kompetensi profesional (BSNP, 2005). Kompetensi pedagogik adalah tuntutan agar guru memahami metodik didaktik, memiliki perangkat pembelajaran termasuk menyusun melaksanakan kegiatan belajar mengajar. Kompetensi kepribadian guru memiliki akhlakul kharimah, dapat diteladani. Kompetensi profesional adalah menguasai mata pelajaran yang akan disampaiakan kepada siswa dan menguasai administrasi untuk mengajar. kopetensi soisal adalah tuntutan berkomunikasi dengan baik (Zainudin, 2016; Suginam, 2019).

Merujuk pada uraian di atas, kepala sekolah melaksanakan penilaian kompetensi guru dalam mengelola kelas. Di SDN 42 Ampenan terdapat 13 guru, $15 \%$ guru tidak memiliki berkas administrasi kelas, 62\% masih kebingungan untuk mengelola administrasi kelas. Guru masih kebingungan cara membuat rencana pelaksanaan pembelajaran (RPP) dan persiapan harian. Hanya $23 \%$ guru yang sudah mengelola administarsi kelas dengn baik dan menguasai dalam mengelolah kelas.

Berdasarkan studi awal yang telah dilakukan, ditemukan data ada beberapa administrasi kelas yang masih belum terselesaikan dengan sempurna. Oleh karena itu, alternatif tindakan yang dilakukan oleh kepala sekolah adalah membina guru tersebut agar mampu mengelola kelas dengan baik melalui pembinaan kepala sekolah dan setiap bulan ada supervisi klinis.

Adapun penelitian ini bertujuan untuk meningkatkan kemampuan guru dalam mengatur kelasnya, meningkatkan profesionalisme guru dalam melaksanakan tugas pokok dan fungsinya sebagai tenaga pengajar, menambah wawasan dan pengetahuan guru tentang kompetensi guru serta meningkatkan mutu guru dalam mengelola administrasi kelas melalui supervisi klinis.

\section{Metode Penelitian}

Metode penelitian yang digunakan dalam penelitian ini adalah penelitian tindakan sekolah. Prosedur yang dilaksanakan dalam penelitian tindakan sekolah ini berbentuk siklus yang akan berlangsung lebih dari satu siklus bergantung dari tingkat keberhasilan dari target yang akan dicapai, dimana setiap siklus bisa terdiri dari satu atau lebih pertemuan. Adapun prosedur penelitian yang dipilih yaitu dengan menggunakan model spiral dari Kemmis dan Mc Taggart (dalam Arikunto, 2008). Subyek penelitian ini adalah guru SD Negeri 42 Ampenan yang berjumlah 13 guru. Teknik pengumpulan datanya menggunakan observasi, wawancara, dan dokumentasi. Teknik analisis data penelitian ini menggunakan analisis deskriptif kualitatif dan kuantitatif. Data yang sudah terkumpul disusun dalam tabel dan dan dinyatakan dalam presentase antara lain jumlah yang baik dan yang kurang baik. Adapun kriteria presentase jika tergolong baik di atas 70\%. Jika tergolong kurang di bawah $30 \%$. 


\section{Hasil Penelitian dan Pembahasan \\ Deskripsi Siklus I}

Siklus I yang dilaksanakan pada hari Kamis tanggal 16 April 2015. Sebelum awal penelitian diadakan rapat dan pembinaan dalam penyusunan administrasi kelas. Penelitian yang dilakukan adalah penelitian penyusunan administrasi kelas. Dalam penelitian ini dilakukan melalui beberapa tahap sebagai berikut:

\section{Perencanaan}

Dalam tahap perencanaan ini, peneliti harus mempersiapkan semua pendukung maupun komponen pelaksanaan penelitian seperti: (a) menetapkan hal yang dikerjakan oleh guru. (b) menyiapkan hal yang akan disusun seperti perencanaan program tahunan, program semester, program RPP, dan silabus. (c) mencermati administrasi yang di selesaikan. (d) memahami isi SK dan KD untuk menyusun program tahunan, program semester, program RPP, dan silabus. (e) kepala sekolah melakukan pembinaan pada guru pada forum kemajuan kompetensi guru SDN 42 Ampenan. (f) kepala sekolah melakukan pelatihan tentang penyusunan administrasi kelas. (g) guru mengaji hasil forum pembinaan dan mengaji SK dan KD untuk menyusun RPP serta mengaji visi dan misi sekolah SDN 42 Ampenan.

\section{Implementasi}

Kegiatan yang dilakukan dalam implementasi yaitu sebagai berikut: (a) Mendata nama-nama guru yang mengumpulakan hasil kinerjanya. (b) Tiap guru menyerahkan hasil kinerja kepada kepala sekolah. (c) Hasil pekerjaan guru tentang administrasi kelas, dikumpulkan di kepala sekolah. Kepala sekolah menyeleksi, menilai, dan mengevaluasi hasil kinerja guru. (d) Kepala sekolah mendata administrasi yang dikerjakan guru. Setelah mendata kepala sekolah mengevaluasi hasil kinerja guru. (e) Setelah mengevaluasi kinerja guru, kepala sekolah memasukan penilaian ke lembar instrumen. (f) Kepala sekolah menganalisis hasil kinerja guru apakah guru tersebut tergolong baik atau masih kurang. (g) kepala sekolah memperesentasi hasil kinerja guru tentang penyusunan administrasi kelas.

\section{Observasi}

Pada saat peneliti mengadakan pengamatan terhadap kinerja guru. Hasil pengamatan peneliti terhadap kinerja guru tentang penyusunan administrasi kelas pada siklus I yaitu sebagai berikut: Masih ada guru yang belum memiliki administrasi kelas secara lengkap, ada guru yang administrasinya lengkap tetapi belum bisa menggunakannya dengan alasan disusunkan oleh orang lain, masih ada guru yang hanya mengkopi paste administrasi kelas dari internet sehingga kebingungan cara penggunaannya.

\section{Refleksi}

Hasil penelitian/observasi kinerja guru pada siklus I dapat digolongkan dalam kategori kurang. Oleh karena itu peneliti menyimpulkan bahwa ketidak berhasilan penyusunan administrasi kelas dengan waktu yang singkat pada siklus I disebabkan beberapa hal di bawah ini: (a) Guru masih kurang berfikir kritis tentang keadaan siswa dan masih juga kurang mengaitkan kondisi siswa yang dialaminya serta lingkungan siswa. (b) Waktu yang disediakan terlalu pendek. (c) Guru masih kesusahan tentang menghitung jam efektif. (d) Kendala dialami guru adalah tentang penyusunan program semester, program tahunan, dan RPP. (e) Guru masih kurang memahami tentang SK dan KD dalam penyusunan RPP

Berdasarkan asumsi di atas, peneliti merancang pada tindakan padaa siklus II dengan tindak lanjut sebagai berikut: (a) Melakukan pembinaan kepada guru. (b) Guru mengaji tentang SK dan KD. (c) Guru menafsir pengalaman yang dilakukan pembelajaran yang dilakukan sebelumnya. 


\section{Deskripsi Siklus II \\ Perencanaan}

Siklus II dilaksanakan pada hari Senin, 11 Mei 2020. perbaikan pada sikulus I.. Pada tahap perencanaan ini, yaitu; (1) mempersiapkan kinerja guru perbaikan dalam perbaikan siklus I, (2) menyiapkan instrumen penelitian yang dilakukan oleh kepala sekolah, (3) guru menyiapkan hal yang akan di evaluasi, (4) menyusun administrasi yang sudah ditetapkan pada awal forum yakni hal-hal yang dinilai dan dijelaskan, dan (5) mempersiapkan daftar nilai.

\section{Implementasi}

Kegiatan yang dilakukan dalam implementasi sebagai berikut: (1) Peneliti melakukan pembinaan pada guru. (2) Guru mgerjakan administrasi kelas. (3) Guru mengumpulkan hasil kinerja. (4) Kepala sekolah menganalisis hasil kinerja guru. (5) kepala sekolah memberikan penilaian kepada guru. (6) Kepala sekolah menganalisis hasil penilaian. (7) Kepala sekolah memberikan hasil kinerja guru apakah guru tersebut tergolong baik atau masih kurang

\section{Observasi}

Kegiatan observasi pada siklus II yaitu mengadakan pengamatan kinerja guru selama menyelesaikan administrasi kelas. Hasil pengamatan selama menyelesaikan administrasi kelas pada siklus kedua banyak guru dapat menyelesaikan dengan sungguh-sungguh di banding pada siklus I, guru sudah bisa membuat sendiri administrasi kelas dengan baik, guru sudah bisa memahami dan menggunakan administrasi secara baik dan benar

\section{Refleksi}

Hasil observasi tes pada siklus II dapat digolongkan dalam kategori baik. Oleh karena itu, peneliti menyimpulkan: (1) Administrasi kelas sudah terkonsep oleh guru, guru bisa membayangkan atau membuat rancangan yang akan dikerjakan. (2) Ada sebagian guru yang masih kurang memahami kondisi sekolah karena masih kurang percaya kepada anak didiknya apakah mampu atu tidak jika guru menyusun rancangan yang dibuat.

\section{Analisis Data Siklus I}

Selanjutnya, peneliti menganalisis hasil penelitian dengan cara menyusun distribusi frekuensi dan mencari nilai rata-ratanya.

Tabel 1. Hasil Penilaian Kinerja Guru

dalam Menyelesaikan Administrasi Kelas Siklus I

\begin{tabular}{|c|c|c|c|c|c|c|c|c|c|c|c|c|c|c|c|c|c|c|c|c|c|c|c|c|}
\hline \multirow[t]{3}{*}{ No } & \multirow[t]{3}{*}{ Nama } & \multicolumn{19}{|c|}{ Penilaian } & \multicolumn{2}{|c|}{ Kritria } & \multicolumn{2}{|c|}{ Presentase } \\
\hline & & \multicolumn{2}{|c|}{1} & \multicolumn{2}{|c|}{2} & \multirow{2}{*}{\multicolumn{3}{|c|}{\begin{tabular}{|c|c|c|}
\multicolumn{2}{|c|}{$\mathbf{3}$} & \multicolumn{4}{|c}{} \\
B & $\mathbf{K}$ & $\mathbf{B}$ \\
\end{tabular}}} & & 5 & \multicolumn{2}{|c|}{6} & \multirow{2}{*}{\multicolumn{2}{|c|}{\begin{tabular}{|c|c|}
\multicolumn{7}{|c|}{} & \\
$\mathbf{B}$ & $\mathbf{K}$ \\
\end{tabular}}} & \multirow{2}{*}{\begin{tabular}{c|c|c|}
\multicolumn{2}{c}{8} \\
$\mathbf{B}$ & $K$
\end{tabular}} & \multirow{2}{*}{\multicolumn{2}{|c|}{\begin{tabular}{l}
\multicolumn{2}{c}{9} \\
$\mathbf{B} K$
\end{tabular}}} & \multirow{2}{*}{\multicolumn{2}{|c|}{\begin{tabular}{|l|l|}
$\mathbf{1 0}$ \\
$\mathbf{B}$ & $\mathbf{K}$ \\
\end{tabular}}} & \multirow{2}{*}{\begin{tabular}{c|c|}
11 \\
B
\end{tabular}} & \multirow{2}{*}{\multicolumn{2}{|c|}{\begin{tabular}{l|l} 
& \\
$\mathbf{B}$ & $\mathbf{K}$
\end{tabular}}} & \multirow{2}{*}{ B } & \multirow[b]{2}{*}{$\mathbf{K}$} \\
\hline & & B & $\mathbf{K}$ & B & $\mathbf{K}$ & & & & $\mathrm{K} B$ & & B & $\mathbf{K}$ & & & & & & & & & & & & \\
\hline 1 & $\begin{array}{l}\text { Budi } \\
\text { Heningsih, } \\
\text { S.Pd }\end{array}$ & $\sqrt{ }$ & & $\sqrt{ }$ & & & $\sqrt{ }$ & & $\sqrt{ }$ & v & $\sqrt{ }$ & & $\sqrt{ }$ & & $\sqrt{ }$ & & V & $\sqrt{ }$ & 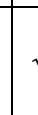 & N & 5 & 6 & $45 \%$ & $55 \%$ \\
\hline 2 & $\begin{array}{l}\text { Hj. Juliati, } \\
\text { S.Pd }\end{array}$ & & $\sqrt{ }$ & & $\sqrt{ }$ & $\sqrt{ }$ & r & V & $\sqrt{ }$ & & $\sqrt{ }$ & & & & & & & $\sqrt{ }$ & & & 5 & 6 & $45 \%$ & $55 \%$ \\
\hline 3 & $\begin{array}{l}\mathrm{Hj} . \\
\text { Hariani, } \\
\text { S.Pd }\end{array}$ & $\sqrt{ }$ & & & $\sqrt{ }$ & $\sqrt{ }$ & & & $\sqrt{ } \sqrt{ }$ & & $\sqrt{ }$ & & $\sqrt{ }$ & & $\sqrt{ }$ & $\sqrt{ }$ & & $\sqrt{ }$ & 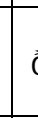 & $\sqrt{ }$ & 5 & 6 & $45 \%$ & $55 \%$ \\
\hline 4 & $\begin{array}{l}\text { Masruni, } \\
\text { S.Pd }\end{array}$ & & $\sqrt{ }$ & & $\sqrt{ }$ & $\sqrt{ }$ & 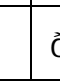 & N & $\sqrt{ }$ & & $\sqrt{ }$ & & $\sqrt{ }$ & & $\sqrt{ }$ & & $\sqrt{ }$ & $\sqrt{ }$ & & $\sqrt{ }$ & 4 & 7 & $36 \%$ & $64 \%$ \\
\hline 5 & $\begin{array}{l}\text { H. } \\
\text { Mustajab, } \\
\text { S.Pd }\end{array}$ & $\sqrt{ }$ & & & $\sqrt{ }$ & $\sqrt{ }$ & J & N & $\sqrt{ }$ & & & & $\sqrt{ }$ & & $\sqrt{ }$ & $\sqrt{ }$ & & $\sqrt{ }$ & & $\sqrt{ }$ & 8 & 3 & $72 \%$ & $27 \%$ \\
\hline 6 & $\begin{array}{l}\text { Bambang } \\
\text { Wirawan, } \\
\text { S.Pd }\end{array}$ & & $\sqrt{ }$ & & $\sqrt{ }$ & $\sqrt{ }$ & 1 & V & & $\sqrt{ }$ & & & $|\sqrt{ }|$ & & $\sqrt{ }$ & & $\sqrt{ }$ & $\sqrt{ }$ & 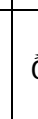 & $\sqrt{ }$ & 5 & 6 & $45 \%$ & $55 \%$ \\
\hline 7 & Maesarah, & & $\sqrt{1}$ & & $\sqrt{ }$ & $\sqrt{1}$ & 1 & $\sqrt{ }$ & $\sqrt{ }$ & & $\sqrt{ }$ & & 1 & $\sqrt{1}$ & $\sqrt{ }$ & & $\sqrt{ }$ & $\sqrt{ }$ & & $\sqrt{ }$ & 4 & 7 & $36 \%$ & $64 \%$ \\
\hline
\end{tabular}




\begin{tabular}{|c|c|c|c|c|c|c|c|c|c|c|c|c|c|c|c|c|c|c|c|c|c|c|c|}
\hline & S.Pd & & & & & & & & & & & & & & & & & & & & & & \\
\hline 8 & $\begin{array}{l}\text { Istikharah, } \\
\text { A.Md }\end{array}$ & & $\sqrt{ }$ & $\sqrt{ }$ & & $\sqrt{ }$ & & $\sqrt{ }$ & & & $\sqrt{ }$ & & & $\sqrt{ }$ & $\sqrt{ }$ & & $\sqrt{ }$ & $\sqrt{ }$ & & 4 & 7 & $36 \%$ & $64 \%$ \\
\hline 9 & $\begin{array}{l}\text { Hj. Siti } \\
\text { Husnah, } \\
\text { S.Pd }\end{array}$ & $\sqrt{ }$ & & & $\sqrt{ }$ & $\sqrt{ }$ & $\sqrt{ }$ & & & $\sqrt{ }$ & & & $\sqrt{ } \mid v$ & & $\sqrt{ }$ & & $\sqrt{ }$ & & $\sqrt{ }$ & 7 & 4 & $64 \%$ & $36 \%$ \\
\hline 10 & $\begin{array}{l}\text { Sahiruddi } \\
\text { n, S.Pd }\end{array}$ & & $\sqrt{ }$ & & $\sqrt{ }$ & $\sqrt{ }$ & $\sqrt{ }$ & & 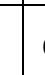 & & $\sqrt{ }$ & $\sqrt{ }$ & $v$ & & & $\sqrt{ }$ & $\sqrt{ }$ & $\sqrt{ }$ & & 5 & 6 & $45 \%$ & $55 \%$ \\
\hline 11 & $\begin{array}{l}\text { Mustikasa } \\
\text { ri,S.Pd }\end{array}$ & & $\sqrt{ }$ & & $\sqrt{ }$ & $\sqrt{ }$ & $\sqrt{ }$ & & 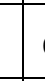 & & $\sqrt{ }$ & $\sqrt{ }$ & $v$ & & & $\sqrt{ }$ & $\sqrt{ }$ & $\sqrt{ }$ & & 5 & 6 & $45 \%$ & $55 \%$ \\
\hline 12 & $\begin{array}{l}\text { Baiq } \\
\text { Mega Nia } \\
\text { R, S.Pd }\end{array}$ & & $\sqrt{ }$ & & $\sqrt{ }$ & $\sqrt{ }$ & $\sqrt{ }$ & & & $\sqrt{ }$ & & & N & $\sqrt{ }$ & & $\sqrt{ }$ & $\sqrt{ }$ & & $\sqrt{ }$ & 4 & 7 & $36 \%$ & $64 \%$ \\
\hline 13 & $\begin{array}{l}\text { Habibul } \\
\text { Azami, } \\
\text { S.Pd I }\end{array}$ & & $\sqrt{ }$ & & $\sqrt{ }$ & $\sqrt{ }$ & $\sqrt{ }$ & & . & & & $\sqrt{ }$ & $v$ & & & $\sqrt{ }$ & $\sqrt{ }$ & $\sqrt{ }$ & & 5 & 6 & $45 \%$ & $55 \%$ \\
\hline & mlah & & & & & & & & & & & & & & & & & & & 66 & 77 & $46 \%$ & $54 \%$ \\
\hline
\end{tabular}

Hasil analisis kinerja guru dalam mengelolah kelas pada siklus I dikatogori baik adalah 46 $\%$. Dan dikategorikan kurang adalah $54 \%$. Dari hasil analisis penelitian ini kepala sekolah melakukan tindakan pembinaan dan melakukan penilaian lagi pada siklus II.

\section{Analisis Data Siklus II}

Selanjutnya, peneliti menganalisis hasil penelitian dengan cara menyusun distribusi frekuensi dan mencari nilai rata-ratanya.

Tabel 2. Hasil Penilaian Kinerja Guru dalam Menyelesaikan Administrasi Kelas pada Siklus II

\begin{tabular}{|c|c|c|c|c|c|c|c|c|c|c|c|c|c|c|c|c|c|c|c|c|c|c|c|c|c|c|}
\hline \multirow[t]{3}{*}{ No } & \multirow[t]{3}{*}{ Nama } & \multicolumn{20}{|c|}{ Penilaian } & & \multicolumn{2}{|c|}{ Kritria } & \multicolumn{2}{|c|}{ Presentase } \\
\hline & & \multicolumn{2}{|c|}{1} & \multicolumn{2}{|c|}{2} & \multicolumn{2}{|c|}{3} & \multicolumn{2}{|c|}{4} & \multicolumn{2}{|c|}{5} & \multicolumn{2}{|c|}{6} & \multirow{2}{*}{\begin{tabular}{|c|c|}
7 & \\
$B$ & $K$ \\
\end{tabular}} & \multirow{2}{*}{\multicolumn{2}{|c|}{\begin{tabular}{|c|c|}
\multicolumn{2}{|c|}{$\mathbf{8}$} \\
$\mathbf{B}$ & $\mathbf{K}$ \\
\end{tabular}}} & \multirow{2}{*}{\multicolumn{2}{|c|}{\begin{tabular}{|c|c|}
\multicolumn{2}{|c|}{9} \\
B & K \\
\end{tabular}}} & \multirow{2}{*}{\multicolumn{2}{|c|}{\begin{tabular}{l}
\multicolumn{1}{|c|}{$\mathbf{1 0}$} \\
$\mathbf{B} \mid \mathrm{K}$
\end{tabular}}} & 11 & \multirow{2}{*}{\multicolumn{2}{|c|}{ B }} & \multirow[b]{2}{*}{ K } & \multirow[b]{2}{*}{ B } & \multirow[b]{2}{*}{$\mathbf{K}$} \\
\hline & & B & $\mathbf{K}$ & B & $\mathbf{K}$ & B & $\mathbf{K}$ & B & $\mathbf{K}$ & B & $\mathbf{K}$ & $\mathbf{B}$ & K B & & & & & & & & B I & & & & & \\
\hline 1 & $\begin{array}{l}\text { Budi } \\
\text { Heningsih } \\
\text {, S.Pd }\end{array}$ & $\sqrt{ }$ & & $\sqrt{ }$ & & $\sqrt{ }$ & & $\sqrt{ }$ & & $\sqrt{ }$ & & $\sqrt{ }$ & $\sqrt{ }$ & & $\sqrt{ }$ & & $\sqrt{ }$ & & $\sqrt{ }$ & & $\sqrt{ }$ & & 11 & & $100 \%$ & $0 \%$ \\
\hline 2 & $\begin{array}{l}\text { Hj. Juliati, } \\
\text { S.Pd }\end{array}$ & $\sqrt{ }$ & & $\sqrt{ }$ & & $\sqrt{ }$ & & $\sqrt{ }$ & & $\sqrt{ }$ & & $\sqrt{ }$ & $\sqrt{ }$ & & $\sqrt{ }$ & & $\sqrt{ }$ & & $\sqrt{ }$ & & $\sqrt{ }$ & & 11 & & $100 \%$ & $0 \%$ \\
\hline 3 & $\begin{array}{l}\mathrm{Hj} . \\
\text { Hariani, } \\
\text { S.Pd }\end{array}$ & $\sqrt{ }$ & & $\sqrt{ }$ & & $\sqrt{ }$ & & $\sqrt{ }$ & & $\sqrt{ }$ & & $\sqrt{ }$ & $\sqrt{ }$ & & $\sqrt{ }$ & & $\sqrt{ }$ & & $\sqrt{ }$ & & $\sqrt{ }$ & & 11 & & $100 \%$ & $0 \%$ \\
\hline 4 & $\begin{array}{l}\text { Masruni, } \\
\text { S.Pd }\end{array}$ & $\sqrt{ }$ & & $\sqrt{ }$ & & $\sqrt{ }$ & & $\sqrt{ }$ & & $\sqrt{ }$ & & $\sqrt{ }$ & $\sqrt{ }$ & & $\sqrt{ }$ & & $\sqrt{ }$ & & $\sqrt{ }$ & & $\sqrt{ }$ & & 11 & & $100 \%$ & $0 \%$ \\
\hline 5 & $\begin{array}{l}\text { H. } \\
\text { Mustajab, } \\
\text { S.Pd }\end{array}$ & $\sqrt{ }$ & & $\sqrt{ }$ & & $\sqrt{ }$ & & $\sqrt{ }$ & & $\sqrt{ }$ & & $\sqrt{ }$ & $\sqrt{ }$ & & $\sqrt{ }$ & & $\sqrt{ }$ & & $\sqrt{ }$ & & $\sqrt{ }$ & & 11 & & $100 \%$ & $0 \%$ \\
\hline 6 & $\begin{array}{l}\text { Bambang } \\
\text { Wirawan, } \\
\text { S.Pd }\end{array}$ & $\sqrt{ }$ & & $\sqrt{ }$ & & $\sqrt{ }$ & & $\sqrt{ }$ & & $\sqrt{ }$ & & $\sqrt{ }$ & $\sqrt{ }$ & & $\sqrt{ }$ & & $\sqrt{ }$ & & $\sqrt{ }$ & & $\sqrt{ }$ & & 11 & & $100 \%$ & $0 \%$ \\
\hline 7 & $\begin{array}{l}\text { Maesarah, } \\
\text { S.Pd }\end{array}$ & $\sqrt{ }$ & & $\sqrt{ }$ & & $\sqrt{ }$ & & $\sqrt{ }$ & & $\sqrt{ }$ & & $\sqrt{ }$ & $\sqrt{ }$ & & $\sqrt{ }$ & & $\sqrt{ }$ & & $\sqrt{ }$ & & $\sqrt{ }$ & & 11 & & $100 \%$ & $0 \%$ \\
\hline 8 & $\begin{array}{l}\text { Istikharah, } \\
\text { A.Md }\end{array}$ & $\sqrt{ }$ & & $\sqrt{ }$ & & $\sqrt{ }$ & & $\sqrt{ }$ & & $\sqrt{ }$ & & $\sqrt{ }$ & $\sqrt{ }$ & & $\sqrt{ }$ & & $\sqrt{ }$ & & $\sqrt{ }$ & & $\sqrt{ }$ & & 11 & & $100 \%$ & $0 \%$ \\
\hline 9 & $\begin{array}{l}\text { Hj. Siti } \\
\text { Husnah, } \\
\text { S.Pd }\end{array}$ & $\sqrt{ }$ & & $\sqrt{ }$ & & $\sqrt{ }$ & & $\sqrt{ }$ & & $\sqrt{ }$ & & $\sqrt{ }$ & $\sqrt{ }$ & & $\sqrt{ }$ & & $\sqrt{ }$ & & $\sqrt{ }$ & & $\sqrt{ }$ & & 11 & & $100 \%$ & $0 \%$ \\
\hline 10 & $\begin{array}{l}\text { Sahiruddi } \\
\text { n, S.Pd }\end{array}$ & $\sqrt{ }$ & & $\sqrt{ }$ & & $\sqrt{ }$ & & $\sqrt{ }$ & & $\sqrt{ }$ & & $\sqrt{ }$ & $\sqrt{ }$ & & $\sqrt{ }$ & & $\sqrt{ }$ & & $\sqrt{ }$ & & $\sqrt{ }$ & & 11 & & $100 \%$ & $0 \%$ \\
\hline 11 & $\begin{array}{l}\text { Mustikasa } \\
\text { ri,S.Pd }\end{array}$ & $\sqrt{ }$ & & $\sqrt{ }$ & & $\sqrt{ }$ & & $\sqrt{ }$ & & $\sqrt{ }$ & & $\sqrt{ }$ & $\sqrt{ }$ & & $\sqrt{ }$ & & $\sqrt{ }$ & & $\sqrt{ }$ & & $\sqrt{ }$ & & 11 & & $100 \%$ & $0 \%$ \\
\hline 12 & $\begin{array}{l}\text { Baiq } \\
\text { Mega Nia } \\
\text { R, S.Pd }\end{array}$ & $\sqrt{ }$ & & $\sqrt{ }$ & & $\sqrt{ }$ & & $\sqrt{ }$ & & $\sqrt{ }$ & & $\sqrt{ }$ & $\sqrt{ }$ & & $\sqrt{ }$ & & $\sqrt{ }$ & & $\sqrt{ }$ & & $\sqrt{ }$ & & 11 & & $100 \%$ & $0 \%$ \\
\hline
\end{tabular}




\begin{tabular}{|c|c|c|c|c|c|c|c|c|c|c|c|c|c|c|c|}
\hline 13 & $\begin{array}{l}\text { Habibul } \\
\text { Azami, } \\
\text { S.Pd I }\end{array}$ & $\sqrt{ }$ & $\sqrt{ }$ & $\sqrt{ }$ & $\sqrt{ }$ & $\sqrt{ }$ & $\sqrt{ }$ & $\sqrt{ }$ & $\sqrt{ }$ & $\sqrt{ }$ & $|\sqrt{ }|$ & $\sqrt{ }$ & 11 & $100 \%$ & $0 \%$ \\
\hline & umlah & & & & & & & & & & & & $\begin{array}{c}14 \\
3\end{array}$ & $\begin{array}{c}100 \\
\%\end{array}$ & \\
\hline
\end{tabular}

Hasil analisis kinerja guru dalam mengelolah administrasi kelas pada siklus II dikatogori baik adalah $100 \%$. Jika dikategorikan kurang adalah $0 \%$. Hasil penelitian kemampuan guru tentang penyusunan administrasi kelas dikategorikan baik.

\section{Interpretasi}

Berdasarkan analisis data tersebut, maka interpretasi yang dapat ditulis dari penelitian ini terhadap objek penelitian yaitu kemampuan guru tentang penyusunan administrasi kelas dikategorikan baik. Kemampuan guru tentang mengelolah administrasi kelas pada siklus I dikatogorikan baik menghasilkan presentase $46 \%$ dan dikategorikan kurang presentasenya adalah 54\% lalu diujicobakan pada siklus II. Adapun perubahan pada siklus II. Perubahan ini diperoleh melalui pembinaan guru kepada kepala sekolah dan pengawas TK/SD. Pada kelemahan siklus II perlu diperhatikan kelemahan yang ada pada siklus I. Kelemahankelemahan pada siklus I itu banyak kebingungan pada guru-guru di SDN 42 Ampenan. Alternatif yang dilakukukan oleh kepala sekolah dan pengawas adalah pembinaan individu pada guru. Hasil kemampuan guru dalam mengelolah administrasi kelas pada siklus II adalah dapat dilihat dari hasil analisis dan mengunakan rumus presentase diperoleh $100 \%$ baik.

\section{Kesimpulan}

Kesimpulan yang diperoleh dari hasil penelitian ini bahwa pada siklus I belum mampu menyelesaikan dengan baik. Hasil yang diperoleh pada siklus I jika dikategorikan baik $46 \%$ dan kategori kurang 54\%. Oleh karena itu, demi meningkatkan kemampuan guru dalam mengelola kelas dilakukan siklus II. Pada siklus II hasil yang diperoleh adalah $100 \%$ dikatakan baik. Dengan demikian dapat disimpulkan bahwa kemampuan guru dalam mengelolah administrasi kelas dapat meningkat dengan diadakanya supervisi klinis.

\section{Saran}

Adapun saran yang dapat disampaikan berdasarkan hasil penelitian ini adalah mengelola administrasi kelas tidak hanya di awal pembelajaran, tapi juga bisa ada pembaharuan di tengah-tengah kegiatan. Apabila ada pembaharuan maka guru membuat hasil revisi yang dibuat pada awal ajaran baru. Secara keseluruhan guru sudah mampu menyusun administrasi kelas dengan baik. Berdasarkan hal tersebut maka saran yang dapat disampaikan adalah hendaknya para pengajar lebih meningkatakan kompetensi sebagai guru.

\section{Daftar Pustaka}

Arikunto, Suharsimi. (2008). Prosedur Penelitian Suatu Pendekatan Praktik. Jakarta : Rineka Cipta.

Depdiknas. (2007). Pedoman Penilaian Hasil Belajar di Sekolah Dasar. Jakarta: Dirjen Manajemen SD dan Menengah

- (2007). Permendiknas Nomor 20 Tahun 2007 tentang Standar Penilaian Pendidikan. Jakarta.

Dirjen PUOD dan Dirjen Dikdasmen. (1996). Pengelolaan Kelas. Seri Peningkatan Mutu 2. Jakarta: Depdagri dan Depdikbud

Kadri, K. (2016). Upaya Meningkatkan Kompetensi Guru Sasaran dalam Proses Pembelajaran Melalui Supervisi Akademik di SMPN 4 Praya. Jurnal Kependidikan: 
Jurnal Hasil Penelitian dan Kajian Kepustakaan di Bidang Pendidikan, Pengajaran dan Pembelajaran, 2(1). doi:https://doi.org/10.33394/jk.v2i1.429

Mulyasa, E. (2003). Manajemen Berbasis Sekolah Konsep, Strategi, dan Implementasi. Bandung: PT. Remaja Rosdakarya.

Kamaludin, K. (2016). Meningkatkan Kompetensi Guru dalam Penyusunan RPP yang Baik dan Benar Melalui Pendampingan Berbasis MGMP di SMPN 4 Praya Timur. Jurnal Kependidikan: Jurnal Hasil Penelitian dan Kajian Kepustakaan di Bidang Pendidikan, Pengajaran dan Pembelajaran, 2(1). doi:https://doi.org/10.33394/jk.v2i1.430

Purnamaraya, S. (2019). Upaya Meningkatkan Kompetensi Guru Kelas dalam Proses Pembelajaran Berdasarkan Kurikulum 2013 Melalui Supervisi Akademik di SD $\begin{array}{llll}\text { Negeri } & 45 & \text { Mataram. Jurnal Paedagogy, } & 6(2),\end{array}$ doi:https://doi.org/10.33394/jp.v6i2.2531

Suginam, A. (2019). Upaya Meningkatkan Kompetensi Guru Kelas dalam Proses Pembelajaran Melalui Supervisi Akademik di SD Negeri 4 Mataram. Jurnal Paedagogy, 6(2), 41-48. doi:https://doi.org/10.33394/jp.v6i2.2530

Zainudin, Z. (2016). Meningkatkan Kompetensi Guru Sasaran dalam Proses Pembelajaran Melalui Supervisi Akademik di SMPN 21 Mataram. Jurnal Kependidikan: Jurnal Hasil Penelitian dan Kajian Kepustakaan di Bidang Pendidikan, Pengajaran dan Pembelajaran, 2(1). doi:https://doi.org/10.33394/jk.v2i1.451 